\title{
THE RECOVERY AND DATING OF CARBON DIOXIDE IN POLAR ICE CORES
}

\author{
A T WILSON and D J DONAHUE \\ Departments of Geosciences and Physics, University of Arizona, \\ Tucson, Arizona 85721
}

\begin{abstract}
A new method is described for recovering trapped $\mathrm{CO}_{2}$ from polar ice cores. The ice is sublimed under vacuum, and $\mathrm{H}_{2} \mathrm{O}$ vapor and $\mathrm{CO}_{2}$ are collected at appropriate cold traps. The application of this method to obtain $\mathrm{CO}_{2}$ from a specific ice core, the conversion of that $\mathrm{CO}_{2}$ to graphite, and the measurement of radiocarbon in the $\mathrm{CO}_{2}$ are described in detail. The potentialities and problems of the method are discussed.
\end{abstract}

\section{INTRODUCTION}

Polar ice cores provide perhaps the best way of obtaining samples for study of the earth's atmosphere at times in the past. There is currently great interest in how the atmosphere has changed with time, and what effect these changes might have had on the earth's climate. The most reliable way of dating samples of ice cores older than the limit of annual isotopic stratigraphy $(\sim 12,000$ yr $\mathrm{BP})$ may be through radiocarbon measurements on $\mathrm{CO}_{2}$ contained in the ice. Previous measurements of ${ }^{14} \mathrm{C}$ in $\mathrm{CO}_{2}$ from ice samples are quite limited. The most successful measurements were made by the Swiss group (Andrée et al, 1986) when they measured ${ }^{14} \mathrm{C}$ in ice samples with masses of ca $20 \mathrm{~kg}$.

Two serious problems must be considered if we are to measure successfully the ${ }^{14} \mathrm{C}$ content of $\mathrm{CO}_{2}$ trapped in polar ice: 1) the cores contain extremely small amounts of carbon. A kilogram of ice contains ca $15 \mu \mathrm{g}$ of carbon as $\mathrm{CO}_{2}$. In addition to making detection of ${ }^{14} \mathrm{C}$ difficult, the small quantities of carbon exacerbate the problem of correcting for background carbon accumulated during sample processing and target preparation;2) the polar ice cores may contain a considerable amount of carbon as solid carbonate particles. It is important to prevent exchange of $\mathrm{CO}_{2}$ carbon with carbonate carbon.

In this paper we discuss our proposed solution to these problems. We describe a method for measuring ${ }^{14} \mathrm{C}$ in the $\mathrm{CO}_{2}$ from samples of ice as small as $3 \mathrm{~kg}$ and present results of a preliminary measurement to test the feasibility of the system.

\section{EXTRACTION OF $\mathrm{CO}_{2}$ FROM ICE}

Two methods have been used previously to extract $\mathrm{CO}_{2}$ from polar ice. Fireman and Norris (1982) melt the ice and trap the released $\mathrm{CO}_{2}$. In the melting process, the $\mathrm{pH}$ of the solution is maintained at a value that is chosen to minimize the amount of carbonate carbon released in the process. The other method (Andrée et al, 1986) requires that the ice be crushed, without melting, so that trapped air is released and $\mathrm{CO}_{2}$ collected in an appropriate cold trap. This procedure is complicated by the necessity always to keep the ice below its melting point. If any ice is allowed to melt, there is a danger of exchange between the $\mathrm{CO}_{2}$ and any carbonate particles (loess) 
in the ice sample. The crushing process releases atmospheric gases trapped in bubbles, but is less effective on gases that have penetrated the ice matrix. The recovery is ca $75 \%$ and is probably not a serious problem for ${ }^{14} \mathrm{C}$ dating. But because of possible fractionation, this incomplete recovery might be a problem if we are interested in doing accurate ${ }^{13} \mathrm{C}^{12} \mathrm{C}$ determinations on the $\mathrm{CO}_{2}$.

A different approach, originally proposed by Alex Wilson, has been used in this work. Polar ice is placed in a glass vacuum container and sublimed to gas. The water vapor, $\mathrm{CO}_{2}$, and other gases produced in the sublimation process are then collected at appropriate cold traps. One advantage of this method is that it is easy to insure that liquid water is never present in the process, thus insuring that there is no exchange between $\mathrm{CO}_{2}$ and carbonate. This can be seen from Figure 1, a pressure-temperature diagram for the $\mathrm{H}_{2} \mathrm{O}$ system. As long as the pressure in the container is below $4.58 \mathrm{~mm} \mathrm{Hg}$, heat can be added to ice, converting it to vapor without producing liquid.

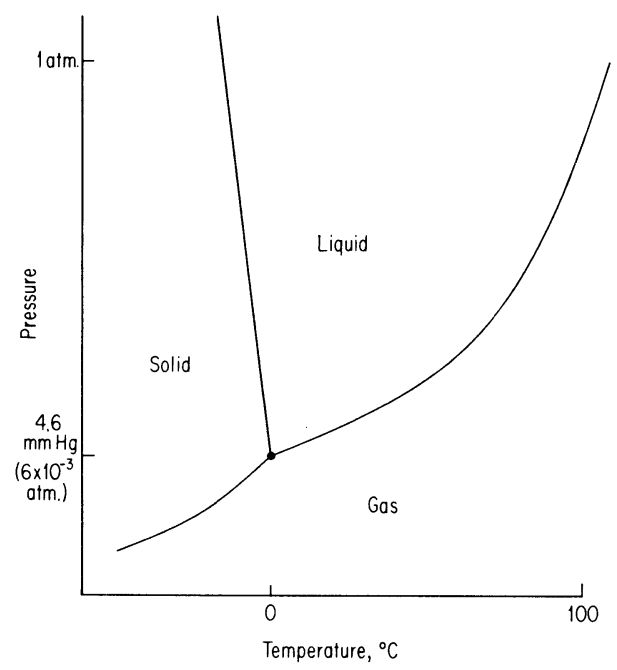

Fig 1. A pressure-temperature diagram for $\mathrm{H}_{2} \mathrm{O}$

The apparatus by which this is achieved is shown schematically in Figure 2. The procedure is as follows: 1) The ice core, with a mass of ca $3 \mathrm{~kg}$, is loaded into the apparatus, and the system is evacuated. 2) The core is "cleaned" by subliming the outer few millimeters of the core into trap A, which is cooled to liquid-nitrogen temperature. This cleaning process also removes contaminating gas from any cracks in the core that may be open to the outside of the core. 3) The remainder of the core is sublimed. Water vapor is collected on traps $\mathrm{B}$ and $\mathrm{C}$, which are cooled to $-80^{\circ} \mathrm{C}$. 4) Atmospheric gases that were trapped in the core pass through cold traps $\mathrm{B}$ and $\mathrm{C}$ and $\mathrm{CO}_{2}$ is collected at trap $\mathrm{D}$, which is a multipass trap held at liquid nitrogen temperature. 


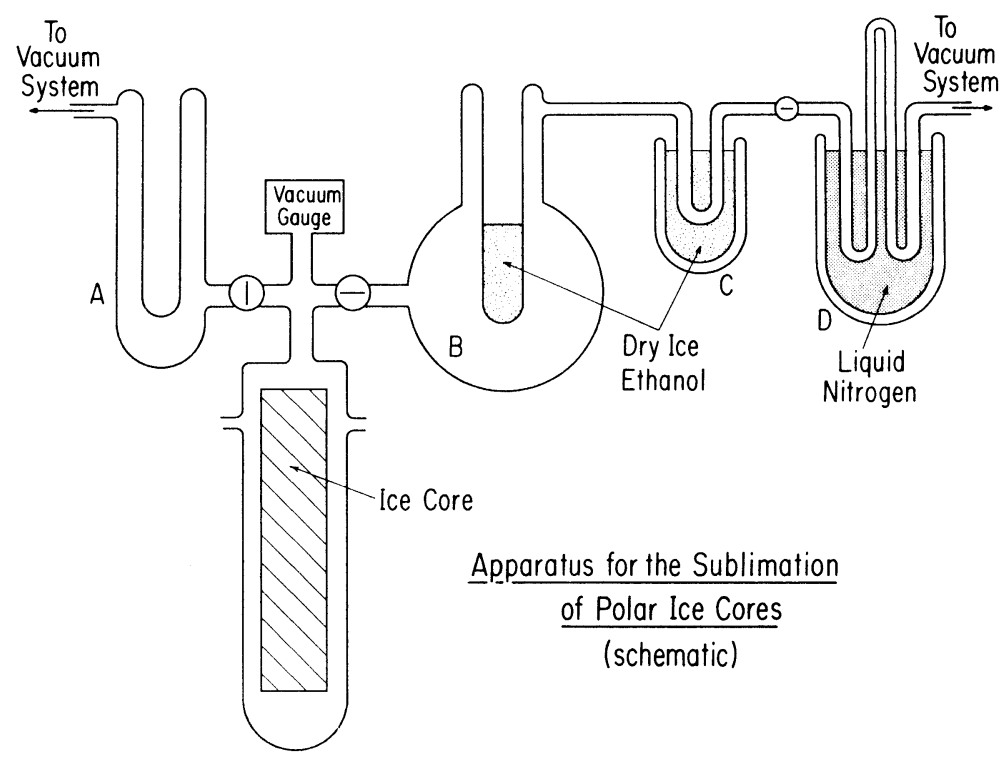

Fig 2. Apparatus for sublimation of polar ice cores (schematic). Operation of the system is described in the text.

In the experiment described here, the remainder of the gases from the core (other than $\mathrm{CO}_{2}$ ) were evacuated to the atmosphere. However, a simple modification of the system will allow us to collect all of the different gases, including $\mathrm{CO}$ and $\mathrm{CH}_{4}$, that were present in the atmospheric sample trapped in the core. Further, the nature of the sublimation process and the design of the system will allow precise measurements of the quantity of various gases released from the core. Finally, after the ice has all sublimed, the carbonates and other solid materials can be collected from the bottom of the container, where they accumulate. These solids can then be analyzed for various isotopic contents.

We have applied this technique to several chunks of freezer ice, and to one piece of polar ice, provided by Paul Mayewski of the University of New Hampshire. The mass of the polar ice was $2.5 \mathrm{~kg}$, and it yielded $65 \mu \mathrm{g}$ of carbon as $\mathrm{CO}_{2}$. The sublimation process took ca $48 \mathrm{hr}$.

\section{TARGET FABRICATION AND ${ }^{14} \mathrm{C}$ MEASUREMENT}

The $\mathrm{CO}_{2}$ from the ice core, containing $65 \mu \mathrm{g}$ of carbon, was introduced into the graphitization system and diluted with dead $\mathrm{CO}_{2}$ by a factor of

$$
\oint=\left[\frac{\text { mass-dilutant }}{\text { mass-sample }}\right]=13.3 \text {. }
$$

It is quite feasible, and desirable, to use a smaller dilution factor. We have made graphite targets from $250 \mu \mathrm{g}$ of carbon. Thus, starting with $65 \mu \mathrm{g}$ of 
carbon, we require a dilution factor of ca 3 , and in future work we will use such dilutions.

The diluted sample, now containing $>900 \mu \mathrm{g}$ of carbon, was converted to graphite for insertion into the accelerator and the fraction of modern of the diluted sample,

$$
\left(\mathrm{F}_{\mathrm{M}}\right)_{\text {measured }}=\frac{\left({ }^{14} \mathrm{C} /{ }^{13} \mathrm{C}\right)_{\text {diluted sample }}}{\left({ }^{14} \mathrm{C} /{ }^{13} \mathrm{C}\right)_{\text {modern-1950 }}}
$$

was determined. This quantity was converted to the fraction of modern of the undiluted sample, $\left(\mathrm{F}_{\mathrm{M}}\right)_{\mathrm{s}}$, by the equation

$$
\left(\mathrm{F}_{\mathrm{M}}\right)_{\text {sample }}=\left(\mathrm{F}_{\mathrm{M}}\right)_{\text {measured }}(1+\oint \mathrm{D})-\left(\mathrm{F}_{\mathrm{M}}\right)_{\mathrm{ct}} f
$$

where

$$
\begin{gathered}
\oint \mathrm{D}=\left[\frac{\text { mass-dilutant }}{\text { mass-sample }}\right] \frac{\left({ }^{13} \mathrm{C} /{ }^{12} \mathrm{C}\right)_{\text {dilutant }}}{\left({ }^{13} \mathrm{C} /{ }^{12} \mathrm{C}\right)_{\text {sample }}} \\
f=\frac{\text { mass-background carbon }}{\text { mass-sample }}
\end{gathered}
$$

and

$$
\left(\mathrm{F}_{\mathrm{M}}\right)_{\mathrm{ct}}=\text { fraction of modern of contemporary carbon }=1.2 \text {. }
$$

This equation is valid if $\left(\mathrm{F}_{\mathrm{M}}\right)_{\mathrm{m}}<<\mathrm{F}_{\mathrm{ct}}$. The mass of background carbon, the numerator in the quantity $f$, was determined by "soaking" the sublimation system in dead $\mathrm{CO}_{2}$ for periods of ca $72 \mathrm{hr}$, converting the $\mathrm{CO}_{2}$ to graphite and determining the amount of ${ }^{14} \mathrm{C}$ present in the graphite. This amount of ${ }^{14} \mathrm{C}$ is converted to a mass of background carbon by assuming that the background carbon is contemporary. We did many experiments during the routine operation of the accelerator that support this assumption. Table 1

TABLE 1

Mass of ice $=2.5 \mathrm{~kg}$
Mass of carbon obtained from ice $=65 \mu \mathrm{g}$
Mass of background carbon $=3 \pm 1.2 \mu \mathrm{g}$
$f=0.05 \pm 0.02$
$\left(\mathrm{~F}_{\mathrm{M}}\right)_{\mathrm{m}}=0.058 \pm 0.002$
$\oint \mathrm{D}=13.4$
$\left(\mathrm{~F}_{\mathrm{M}}\right)_{\mathrm{s}}=(0.058 \pm 0.002)(14.4)-1.2(0.05 \pm 0.02)$
$=0.77 \pm\left\{(0.03)^{2}+(0.024)^{2}\right\}^{1 / 2}$
$=0.77 \pm 0.04$
${ }^{14} \mathrm{C}$ age $=2100 \pm 400 \mathrm{yr} \mathrm{BP}$


presents the result of the experiment performed on a polar ice core from the Beardmore region of Antarctica. An interesting observation from this table is that even for a result of $2000 \mathrm{yr} \mathrm{BP}$, the uncertainty from background is comparable to the uncertainty from ${ }^{14} \mathrm{C}$ counting.

\section{DISCUSSION}

The results in Table 1 illustrate that, as pointed out by the Swiss team three years ago (Andrée et al, 1986), the correction for background is a very serious problem when dealing with ice cores, or with any small samples. Our future efforts will be directed towards reducing the bacground and reducing the uncertainty of its value. Mark II of the sublimation system will be constructed so that it can be baked and pumped to high vacuum. After such treatment, the system will not be exposed to atmospheric gases. With sufficient effort, we expect to be able to reduce backgrounds significantly. Figure 3 presents a series of curves that illustrate the effect of such reductions. It shows plots of the uncertainty in ${ }^{14} \mathrm{C}$ age measurements as a

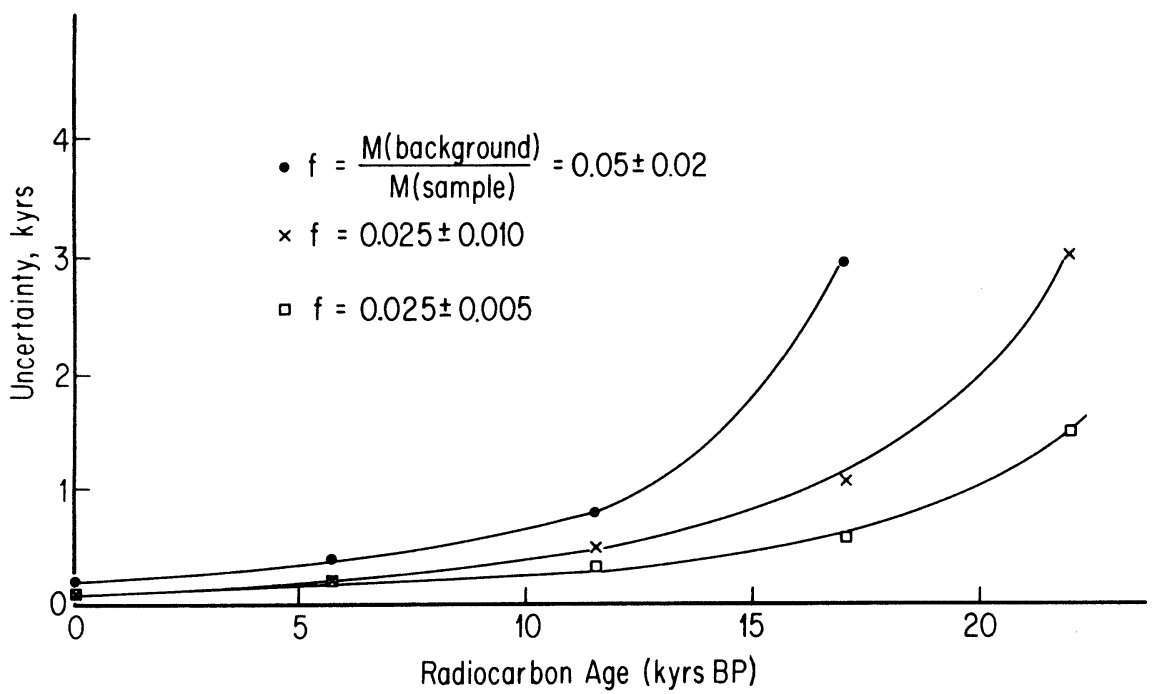

Fig 3. Plots of the uncertainty in ${ }^{14} \mathrm{C}$ measurements on $\mathrm{CO}_{2}$ from a $3 \mathrm{~kg}$ ice core $v s{ }^{14} \mathrm{C}$ age, for several conditions.

function of ${ }^{14} \mathrm{C}$ ages for several conditions. The curve defined by solid points shows the current status of our measurements, as determined by the experiments described in Section III. For a ${ }^{14} \mathrm{C}$ age of ca $15,000 \mathrm{yr}$, the uncertainty is $2000 \mathrm{yr}$. The curve defined by the open squares illustrates the situation if both the background and its uncertainty were reduced by a factor of two. In this case, the error for a ${ }^{14} \mathrm{C}$ age of $20,000 \mathrm{yr}$ is $1000 \mathrm{yr}$. We expect to be able to achieve this condition. 


\section{REFERENCES}

Andrée, M, Beer, J, Loetscher, H P, Moor, E, Oeschger, H, Bonani, G, Hoffman, H J, Morenzoni, E, Nessi, M, Suter, M and Wölfli, W, 1986, Dating polar ice by ${ }^{14} \mathrm{C}$ accelerator mass spectrometry, in Stuiver, $\mathrm{M}$ and $\mathrm{Kra}, \mathrm{R} \mathrm{S}$, eds, Internatl ${ }^{14} \mathrm{C}$ conf, 12th, Proc: Radiocabon, v 28, no.2A, p 417-423.

Fireman, E L and Norris, T L, 1982, Ages and composition of gas trapped in Alan Hills and Byrd core ice: Earth Planetary Sci Letters, v 60, p 339-349. 